\title{
Kuhn's “wrong turning” and legacy today
}

\author{
Yafeng Shan ${ }^{1}$
}

Received: 23 August 2017 / Accepted: 16 February 2018 / Published online: 28 February 2018

C The Author(s) 2018. This article is published with open access at Springerlink.com

\begin{abstract}
Alexander Bird indicates that the significance of Thomas Kuhn in the history of philosophy of science is somehow paradoxical. On the one hand, Kuhn was one of the most influential and important philosophers of science in the second half of the twentieth century. On the other hand, nowadays there is little distinctively Kuhn's legacy in the sense that most of Kuhn's work has no longer any philosophical significance. Bird argues that the explanation of the paradox of Kuhn's legacy is that Kuhn took a direction opposite to that of the mainstream of the philosophy of science in his later academic career. This paper aims to provide a new way to understand and develop Kuhn's legacy by revisiting the development of Kuhn's philosophy of science in 1970s and proposing a new account of exemplar. Firstly, I propose my diagnosis of Kuhn's "wrong turning" by identifying Kuhn's two novel contributions: the introduction of paradigm and the proposal of the incommensurability thesis. Secondly, I argue that Kuhn made a conceptual/terminological turn from paradigm to theory, which undermined Kuhn's novel contributions. Thirdly, I propose a new articulation of exemplar and propose an exemplar-based approach to analysing the history of science. Finally, I show how the exemplar-based approach can be applied to analyse the history of science by my case study of the early development of genetics.
\end{abstract}

Keywords Exemplar - The exemplar-based approach · Kuhn · The origin of genetics

Yafeng Shan

yafeng.shan@durham.ac.uk

1 Department of Philosophy, Durham University, 51 Old Elvet, Durham DH1 3HN, UK 


\section{Introduction: Bird on the paradox of Kuhn's legacy}

Alexander Bird (2002) indicates that the significance of Thomas Kuhn in the history of philosophy of science is somehow paradoxical. On the one hand, Kuhn was one of the most influential and important philosophers of science in the second half of the twentieth century. On the other hand, nowadays there is little distinctively Kuhn's legacy in the sense that most of Kuhn's work has no longer any philosophical significance. ${ }^{1}$ Bird argues that the explanation of the paradox of Kuhn's legacy is that Kuhn took a direction opposite to that of the mainstream of the philosophy of science in his later academic career. From Bird's point of view, since the 1970s, more and more philosophers became sympathetic to a naturalistic approach to philosophical issues, whereas Kuhn took a more a priori approach. This is what Bird called Kuhn's wrong turning. A consequence of this methodological turn is that Kuhn failed to articulate and explore the concept of paradigm as exemplar in a naturalistic approach. Bird (2002, 2005,2008 ) also proposes a naturalised account of the incommensurability thesis and argues that it is more promising and plausible than Kuhn's late versions of incommensurability (1989, 1990, 1993, 2000a, b). To sum up, Bird argues the success of Kuhn's (1962) book The Structure of Scientific Revolutions (SSR) is due to his naturalised account of the history and practice of science in terms of paradigms. (In particular, Kuhn uses empirical evidence to argue for the theory-dependence of observation.) So it is not surprising that Kuhn's late work with a less naturalistic approach leaves little impact on contemporary philosophy of science. This is why Bird argues that Kuhn's methodological turn in the 1970s explains the paradox of Kuhn's legacy.

But why did Kuhn make such a methodological turn? Bird provides two further explanations. Firstly, the machinery that Kuhn needed to further develop the incommensurability thesis was not available to him. In Bird's words, "the central idea of The Structure of Scientific Revolutions was before its time in an important respect." (Bird 2002, p. 444) Secondly, though Kuhn was strongly inclined to be a philosopher, he had little philosophical training and was unaware of the naturalistic turn in the philosophical world in his time.

Thus, Bird's argument can be reformulated as follows:

$\mathrm{P} 1$. Kuhn's most important contribution is his naturalistic account of the history of science in $S S R$ in terms of paradigm.

P2. Kuhn made a methodological turn in the 1970s, namely from a naturalistic approach to an a priori approach.

P3. Kuhn's methodological turn makes him fail to articulate and explore the concept of paradigm in a naturalistic way.

C. Therefore, Kuhn's most important contribution is undermined by his methodological turn. Thus, Kuhn's legacy is really thin today.

\footnotetext{
1 It should be noted that Bird's claim is not that there is an apparently lacking influence of Kuhn's work in contemporary philosophy of science. Rather what Bird explicitly means is that "there is no specifically Kuhnian school in the philosophy of science. Nor is Kuhn's most characteristic thesis- the thesis of incommensurability - regarded any longer as having the philosophical significance that Kuhn claimed for it" (Bird 2002, pp. 443-444).
} 
I agree with Bird on the point that Kuhn made some "wrong turning" in the sense it prevents his work becoming more promising and better received. ${ }^{2}$ I also agree that Kuhn made a methodological turn in the 1970s, and Bird's naturalised account of the incommensurability thesis is more promising than Kuhn's late versions of incommensurability. However, I find Bird's diagnosis still incomplete. Firstly, Kuhn's “wrong turning" is more than methodological. As Bird points out, in the presidential address to the Philosophy of Science Association in 1990, Kuhn made no mention at all of paradigms, which was his major contribution in SSR. In fact, as I shall argue in Sect. 3, Kuhn has been deliberately avoiding talking of paradigm since 1970s. Thus, there is also a conceptual/terminological turn in Kuhn's philosophy of science. Secondly, even if Bird's attempt to naturalise the incommensurability thesis is promising, I contend that it is not the only way to develop Kuhn's work to contribute to contemporary philosophy of science. In this paper, I aim to provide a new way to understand and develop Kuhn's legacy by revisiting the development of Kuhn's philosophy of science in 1970s and proposing a new account of exemplar.

My strategy of analysing Kuhn's “wrong” turning will be centrally concerned with Kuhn's novel contributions. I shall examine what makes Kuhn's early philosophy of science so revolutionary and influential. In other words, what are the novel contributions made by early Kuhn which might be Kuhn's legacy for today? Secondly, I shall identify the obstacles to the further articulation of Kuhn's novel contributions: Why are these "revolutionary and influential" parts of Kuhn's philosophy left without substantial or lasting impact on contemporary philosophy of science? In Sect. 2, I shall propose my own diagnosis by identifying that Kuhn's two novel contributions. In Sect. 3, I shall argue that Kuhn made a conceptual/terminological turn from paradigm to theory, which undermined Kuhn's novel contributions. In Sect. 4, I shall propose a new articulation of exemplar and propose an exemplar-based approach to analysing the history and practice of science. In Sect. 5, I shall show how the exemplar-based approach can be applied to account for the early development of genetics.

\section{Kuhn's novel contributions}

In this section, I shall argue that Kuhn made two major novel contributions in SSR. Along with Bird, I contend that Kuhn's introduction of the concept of paradigm (as an alternative to theory to characterise the history and practice of science) in SSR is his most novel and significant contributions to the philosophy of science $(1962,1970)$. It is a novel move in the history of philosophy of science in two senses. Firstly, it is really novel to analyse and understand the history and practice of science in terms of paradigms. Traditionally, without argument, philosophers (e.g. Popper 1959; Nagel 1961; Suppe 1977) analyse scientific knowledge and the history of science in terms of theories. Theories are taken for granted as the typical unit to represent an episode of

\footnotetext{
${ }^{2}$ It should be highlighted that I am sympathetic to Bird's view that Kuhn made a "wrong turning", but I only accept a weaker version of the paradox of Kuhn's legacy. The crucial difference is that Bird is explicit on the point that Kuhn's "wrong turning" made his legacy in the philosophy of science today extraordinarily thin, while I contend that without Kuhn's "wrong turning", his work would have been more promising and better received.
} 
the history of science. For example, the Copernican revolution was widely construed as a theory-change from the Ptolemaic theory to the Copernican theory. It is Kuhn who first made philosophers seriously reconsider the legitimacy of the application of theory as the unit of analysis in the philosophical examination of the history of science. Kuhn (1970, p. 182) insightfully points out that the unit of analysis in philosophising the history of science should be a broader unit, i.e. what is shared by a scientific community, rather than a single scientific theory, which "connotes a structure far more limited in nature and scope than the one required".

Accordingly, Kuhn suggests that the history of a science is a cyclic process alternating the period of normal science, in which most scientists work under one dominating paradigm, with the period of scientific revolution, in which there are multiple competing paradigms. In the period of normal science, scientists' main task is to solve puzzles or problems of the accepted paradigm. Sometimes a paradigm falls into a state of crisis due to some internal and external factors when the scientists begin to lose their confidence in the ability and effectiveness of the paradigm's puzzle-solving machinery. For Kuhn (1970, p. 181), a crisis is "the usual prelude" to a scientific revolution, or paradigm-shift. In the period of scientific revolution, there is no universally accepted paradigm in the community of scientists. Multiple paradigms compete with each other until the establishment of a new period of normal science when one of the competing paradigms wins the support of the majority and most scientists again work together to solve its puzzles.

Since the publication of SSR, many alternative units of analysis have been proposed inspired by Kuhn's paradigm. Lakatos' research programme (1968), ${ }^{3}$ Laudan's research tradition (1977), ${ }^{4}$ and Darden and Maull's field $(1977)^{5}$ are among the most famous ones. Thus, it is not difficult to see how Kuhn's novel proposal of the conception of paradigm revolutionised the philosophical analysis of scientific knowledge and the history of science in the 1960s and 1970s.

Some may challenge the view that Kuhn's concept of paradigm is really novel. For example, Ludwik Fleck (1935) introduced a similar community-based concept, thought style, to analyse the history of science, and Kuhn himself (1979) also acknowl-

\footnotetext{
3 Lakatos is explicit on the point that his "research programme" is a reconstruction of "paradigm" in his defence of Popperian philosophy of science against Kuhn's challenge: "Indeed, my concept of a 'researchprogramme' may be construed as an objective, 'third-world' reconstruction of Kuhn's concept of 'paradigm': thus the Kuhnian 'Gestalt-switch' can be performed without removing one's Popperian spectacles" (Lakatos 1968, p. 182n87).

4 Laudan's conception of research tradition is an alternative to Kuhn's paradigm and Lakatos' research programme as the unit of analysis in the history of science: "[I]t has been suggested by Kuhn and Lakatos that the more general theories, rather than the more specific ones, are the primary tool for understanding and appraising scientific progress... I share this conviction in principle, but find that accounts hitherto given of what these larger theories are, and how they evolve, are not fully satisfactory... [T] his chapter will be devoted to outlining a new account of the more global theories (which I shall be calling research traditions)" (Laudan 1977, p. 72).

5 Although Darden and Maull's conception of field is also influenced by Stephen Toulmin's conception of discipline (1972), it follows the trend in the philosophy of science at that time to adopt a broader unit of analysis, led by Kuhn and Lakatos: "Other current broader categories include Imre Lakatos's 'research programme,' ... and Thomas Kuhn's 'paradigm' or 'disciplinary matrix'...” (Darden and Maull 1977, p. 45n5).
} 
edged that he knew Fleck's work before SSR. It has been debated (e.g. Babich 2003; Knoblauch 2010) to what extent Kuhn's paradigm may have been influenced by Fleck's thought style or thought collective. Despite the similarity between paradigm and thought style, I still contend that Kuhn's introduction of the concept of paradigm is a novel contribution to the philosophy of science in the 1960s. Nicola Mößner (2011) has already shown that there are substantial differences between Kuhn's paradigm and Fleck's thought style. In addition, I would like to highlight that it is novel for Kuhn to distinguish two senses of paradigm: ${ }^{6}$ paradigms as disciplinary matrices, and paradigms as exemplars. The broad sense of paradigm, also called disciplinary matrix, is a consensus among a community of scientists, which consists of symbolic generalisations, ${ }^{7}$ values, ${ }^{8}$ models, ${ }^{9}$ and exemplars. The narrow sense of paradigm, also called exemplar (an essential constituent of the disciplinary matrix), refers to a problem solution. Such a distinction is Kuhn's attempt to articulate the nature and structure of a paradigm. In particular, the narrow sense of paradigm is really novel in the sense that by introducing "exemplar", Kuhn tries to emphasise the significance of the problemsolving, problem-solution learning, analogical reasoning, and tacit knowledge in the practice of science. All these were overlooked by most philosophers of science in the 1960s. ${ }^{10}$ Even Kuhn (1970, p. 187) himself explicitly identifies "paradigm as exemplar" as the most novel aspect of SSR. This narrow sense of paradigm and its philosophical implication is absent from Fleck's conception of thought style. Therefore, the introduction of the concept of paradigm as a new unit of analysis to examine the history and practice of science is Kuhn's one significant novel contribution.

In addition, the incommensurability thesis ${ }^{11}$ is Kuhn's other novel contribution to the twentieth century's philosophy of science. The basic idea of the incommensurability thesis is that there is a difficulty of comparing two successive paradigms as disciplinary matrices in the paradigm-shift. ${ }^{12}$ The shift from one paradigm from

\footnotetext{
6 It should be noted that this distinction was not a novel idea in the first place (i.e. the first edition of SSR), but was introduced in the postscript of the second edition of SSR as a response to the criticism that there were too many different senses of paradigm. Nevertheless, it does not undermine the novelty of Kuhn's distinction between paradigm as disciplinary matrix and paradigm as exemplar.

7 Symbolic generalisations are symbolic expressions of scientific hypotheses, which can be manipulated mathematically. Newton's second law (i.e. $\mathrm{F}=\mathrm{ma}$ ) is such a case.

8 The values of a disciplinary matrix, which are shared by the members under it, include accuracy, consistency, scope, simplicity, fruitfulness, and so on.

9 Models, for Kuhn (1970, p. 184), designate two different classes. On the one hand, models include "the metaphysical commitments" or "ontological models" like the belief that the heat of a body is the kinetic energy of its constituent particles. On the other hand, models also encompass the "heuristic models and analogies" in accordance with which phenomena from a given class may be treated as if they were something else entirely. Take an example from Mendelian genetics: Genes carried on chromosomes can be understood as beads strung on a wire.

10 Michael Polanyi's book (1966) is an exception.

11 The claim that the incommensurability thesis is Kuhn's novel contribution seems controversial to some. In the same year when the first edition of SSR was published, Paul Feyerabend (1962) proposed his thesis of incommensurability. Fleck $(1927,1939)$ talked of the incommensurability of concepts or ideas even earlier. However, it is novel to formulate the incommensurability thesis in terms of paradigm. It is in this sense that the (paradigm-based) incommensurability thesis is Kuhn's another novel contribution.

12 It should be noted that Kuhn is very explicit on the point that incommensurability does not imply incomparability.
} 
another cannot be simply explained by some universal standard of rationality (e.g. Popper's falsifiability criterion). In the 1960s, Kuhn's incommensurability thesis provided an alternative way to understand and analyse scientific progress and scientific change. Furthermore, it highlighted the discontinuity of the history of science and the complexity of the practice of science. Traditional philosophical understandings of scientific change and rationality (e.g. the conventional progressive account and Popper's falsificationist account) were seriously challenged by Kuhn's incommensurability thesis. Thus, I argue that this is another major novelty made by Kuhn in the 1960s.

Of course, it can be argued that Kuhn's novel contributions are more than these. For example, some may argue that Kuhn's real novel contribution is to argue that the history of science is discontinuous, while other may identify Kuhn's contribution as the identification of the social factor in the practice of science. But I contend all these contributions are dependent on the conceptions of paradigm and incommensurability.

\section{Kuhn's conceptual/terminological turn and "wrong turning"}

However, Kuhn's novel contributions, as Bird argues, are not as well developed as expected. Neither paradigm as exemplar nor paradigm as disciplinary matrix has been seriously articulated further. Nor has an exemplar-based account of scientific change or history of science explored with a detailed historical case. Kuhn's later interpretations of incommensurability are poorly received. Why has the significance of what Kuhn achieved in SSR not been fully recognised? Before answering this question, I shall point out that there is a peculiar phenomenon. After the 1970s, Kuhn (1977), like other philosophers at that time, began conflating "theory" with "paradigm", and he ended up never using "paradigm" (e.g. Kuhn 1982, 1983, 1987). In particular, after 1970 Kuhn seldom used the concept of paradigm or exemplar to analyse the history of science and scientific change. ${ }^{13}$ It is surprising that Kuhn, who once strongly opposed the use of the concept "theory" to analyse the practice and history of science (Kuhn 1962, 1970), ignored the substantial difference between paradigm and theory identified by himself. It is also extraordinary that neither paradigm as exemplar as "the central element of what [I] now [take] to be the most novel and least understood aspect of [SSR]" (Kuhn 1970, p. 187), nor paradigm as disciplinary matrix as "the one that [I believe] most urgently needs philosophical attention" (Kuhn 1974, p. 460) has never been further articulated, or even mentioned again, even by himself, since 1974. Instead, Kuhn begins examining the history and practice of science in terms of theory. Kuhn articulates the characteristics of a good "theory" rather than a good paradigm (1977), talks of "theory-choice" rather than "paradigm-choice" (1983), and reinterprets the incommensurability thesis in terms of theory (1989). Thus, I argue that this conceptual/terminological turn (from paradigm to theory) is another important change in Kuhn's philosophy of science, in addition to the methodological turn. Note

\footnotetext{
13 It should be noted that Kuhn's "Second thoughts on paradigm" was not a post-1970 work, since it was written for the 1969 Illinois Symposium on the structure of scientific theories, although it was published for the first time in the conference volume edited by Suppe in 1974.
} 
that the conceptual/terminological turn is much more than a linguistic issue. It impedes the further development of the concept of paradigm, and thus undermines Kuhn's contribution as the proposal of the concept of paradigm.

Moreover, I shall argue that Kuhn's conceptual/terminological turn also indirectly leads to undermine other contribution of his, namely the introduction of the incommensurability thesis. Initially, Kuhn (1962) implicitly characterised the incommensurability thesis in three ways, namely methodological, semantic, and cognitive. ${ }^{14}$ However, since 1970, Kuhn began focusing on the semantic aspect of the incommensurability thesis. He attempted to interpret incommensurability in terms of untranslatability, non-overlapping lexicons, and so on. As Kuhn (1982, p. 684n3) admitted, "I would no longer [speak of the methodological incommensurability] ${ }^{15}$ except to the considerable extent that the [methodological aspect of incommensurability is a] necessary consequence of the language-learning process". However, this move is characterised as the "journey up [a] dead end" by Bird (2002, p. 463). I shall argue that Kuhn's conceptual/terminological turn underlies this move. As Kuhn made the conceptual/terminological turn from paradigm to theory, he began analysing the history and practice of science in terms of theory. Thus, the incommensurability thesis immediately becomes narrowly scoped. If the incommensurability thesis were to be articulated in terms of paradigm as disciplinary matrix, it would be analysed by examining the differences in the symbolic generalisations, models, values, and exemplars. If the incommensurability thesis were to be articulated in terms of paradigm as exemplar, it would be analysed by examining the differences in the problems to be investigated and the corresponding solutions. Either way it seems promising to investigate all of the methodological, semantic, and cognitive aspects of the incommensurability thesis. However, if the incommensurability thesis were to be articulated in terms of theory as Kuhn did, it would be difficult to see how two theories could be compared methodologically or cognitively. The only aspect that matters here is the semantic one. So, it is not surprising that Kuhn shifted his focus onto semantic incommensurability from the 1970s. It is a natural consequence of his conceptual/terminological turn. In short, because Kuhn did not talk of paradigm, nor articulate the concept paradigm, it seems natural for him to shift his attention to the semantic aspect of incommensurability, and prevents him from developing the methodological or cognitive aspects further. Therefore, the incommensurability thesis became less fruitful and promising as a result of Kuhn's conceptual/terminological turn. Bird's naturalised account of incommensurability $(2002,2005,2008)$ has already successfully showed how the cognitive aspect of the incommensurability thesis can be developed in terms of exemplar rather than theory.

Thus, my explanation of the paradox of Kuhn's legacy is as follows.

(a) Kuhn's two major novel contributions to the twentieth-century philosophy of science are (1) the introduction of the concept of paradigm as an alternative to

\footnotetext{
14 Kuhn never used the phrases "methodological incommensurability", "semantic incommensurability", or "cognitive/perceptual incommensurability". For a fuller articulation of the three aspects of Kuhn's incommensurability thesis, see Sankey $(1993,1994)$.

15 Kuhn's original expression in the text is "differences in method, problem-field, and standards of solution" (Kuhn 1982, p. 684n3).
} 
theory to analyse the practice and history of science; (2) and the proposal of the incommensurability thesis as a new account of scientific change.

(b) Kuhn made a conceptual/terminological turn in the 1970 s, which withdrew his novel contribution (1).

(c) Kuhn's conceptual/terminological turn underlies his focussing attention upon the semantic incommensurability, to the detriment of the methodological and cognitive aspects.

(d) From (b) and (c), we can conclude that it is Kuhn's failure to explore and articulate his novel concept of paradigm as exemplar that makes the incommensurability thesis less fruitful and plausible, which means that his novel contribution (2) is undermined.

(e) Therefore, from (b) and (d), Kuhn's failure to explore and articulate his novel concept of paradigm as exemplar well explains the paradox of Kuhn's legacy.

It should be noted that Bird (2002, p. 461, 2005, p. 114) seems to recognise Kuhn's conceptual/terminological turn. However, Bird fails to appreciate its significance fully. On the one hand, the conceptual/terminological turn is just implicitly mentioned in Bird's analysis. It is in this sense that I find Bird's diagnosis incomplete. On the other hand, Bird regards the conceptual/terminological turn as a consequence of the methodological turn. In contrast, I argue that even if the conceptual/terminological turn does not necessarily imply the methodological turn, the former is at least as fundamental as the latter. They are mutually connected and together consist in Kuhn's "wrong turning" in the 1970s.

\section{A new interpretation of exemplar and the exemplar-based approach}

Although both Bird and I argue that Kuhn's failure of exploring and articulating his novel concept of paradigm as exemplar is key to the explanation of the paradox of Kuhn's legacy, there is a crucial difference between Bird's and my diagnosis. For Bird, the nature of Kuhn's wrong turning is methodological, while I insist that it is much more complicated. Firstly, though I agree with Bird on the point that there was a methodological turn in Kuhn's philosophy of science, it was not the only change. Even Bird (2002, p. 461) also admits that Kuhn shifted his philosophical focus from a paradigmbased account of history of science to the reinterpretation of the incommensurability thesis. However, Bird argues that this focus-shift is a result of Kuhn's methodological turn, while I argue that Kuhn's methodological turn, conceptual/terminological turn, and focus-shift are mutually influenced in a complex way. To some extent it can also be argued that Kuhn's methodological turn, conceptual/terminological turn, and focus-shift reflect the different aspects of a deeper shift in Kuhn's philosophy of science since the 1970 s.

Secondly, though I also agree with Bird on the point that Kuhn's early naturalistic approach is significant and promising, I think that it is not the only significant and promising element in SSR. Nor am I convinced that a naturalistic approach to exemplar and incommensurability thesis is the only promising way to develop the concept of exemplar and the incommensurability thesis. In contrast, Kuhn's incommensurability thesis can be developed pluralistically, as his original version suggests. Chang (2012), 
for example, develops a methodological incommensurability thesis to illustrate the chemical revolution.

Moreover, I shall argue that there are many other aspects of Kuhn's conception of exemplar to be explored. For example, though it is never explicitly stated, Kuhn's concept of paradigm suggests a practice-oriented philosophy of science, which is eventually echoed by the recent practical turn in philosophy of science. For many philosophers (e.g. Chang 2014, p. 67; Soler et al. 2014, pp. 21-22; Waters 2014, p. 121; Giere 2011, p. 61), the central issue in contemporary philosophy of science should and has gradually shifted from what scientists find out to how scientists find out, and from scientific (theoretical) knowledge to scientific practice. Kuhn's very first definition of paradigm was practice-oriented (1970, p. 10): paradigms are "some accepted examples of actual scientific practice-examples which include law, theory, application, and instrumentation together-[which] provide models from which spring particular coherent traditions of scientific research." In addition, the practice-oriented implication of Kuhn's philosophy is also reflected in his emphasis on the significance of the activities of puzzle-solving in the history of science. Some (e.g. Nickles 2003; Rouse 2003) have already recognised the significance of the practical aspect of exemplar. For instance, as Joseph Rouse (2003, p. 107) suggests, paradigms as exemplars can be understood as "exemplary ways of conceptualizing and intervening in particular situations." Thus, along with Rouse, I argue that a more rigorous practice-based articulation of exemplar will contribute to the ongoing movement termed philosophy of science in practice. More specifically, I contend that a better articulation of exemplar will provide a useful tool to analyse the history and practice of science. In the rest of this section, I will propose a new interpretation of exemplar and correspondingly an exemplar-based approach to analysing the development of scientific practice.

For Kuhn, exemplars as problem-solutions play an indispensable role in the practice of puzzle-solving. It is Kuhn's novel contribution to introduce the significance of puzzle-solving in the scientific practice into the philosophy of science community. However, Kuhn's concept of exemplar still lacks a fuller articulation. In other words, Kuhn's own definition of exemplar is too thin and premature. Many significant problems concerning exemplars are yet to be explored. Firstly, Kuhn says little on how an exemplar is first established or constructed further. As Thomas Nickles (2012, p. 120) asks, "Where do [exemplars] initially come from?" 16 Although Kuhn is famous for his rejection of the sharp distinction between the context of discovery and of justification and accusing philosophers of ignoring the "temporal development of a theory", Kuhn does not provide a sophisticated account of the construction and temporal development of an exemplar. Secondly, in his elaboration, Kuhn's exemplar is simply exemplified by the examples in the textbooks, lectures, and laboratory exercises. These examples are helpful to provide a rough idea of the application of the exemplars. However, the constituents of an exemplar are never explicitly explicated. Nor is a historical example

\footnotetext{
16 However, Nickles (2012) still pays insufficient attention to articulate the process of the construction of an exemplar.
} 
of an exemplar articulated in an explicit way. ${ }^{17}$ Thirdly, Kuhn's exemplar (as a problem-solution) implicitly assumes some pre-existing problems. But where are these pre-existing problems from? Although Kuhn (1970, p. 103) contends that the shift of accepted exemplars in a scientific revolution necessitates the redefinition of research problems, he says little on how the research problems are defined or redefined. Nor is it clear whether problem-defining is a task involving the construction of an exemplar. The significance of problem-defining seems not to be fully recognised by Kuhn. Fourthly, Kuhn fails to explore the characteristics of a good exemplar. ${ }^{18}$ It is unclear what makes some exemplars successfully accepted, while others neglected or abandoned. ${ }^{19}$ Fifthly, Kuhn is implicit on how an exemplar is or the constituents of an exemplar are used or applied to guide the subsequent research, including constructing a new exemplar, proposing new research problems, solving other problems.

To sum up, Kuhn's definition of exemplar is not well articulated mainly in five ways:

1. The construction of an exemplar is unclear;

2. The constituents of an exemplar are unclear;

3. No detailed historical example of an exemplar is illustrated;

4. What makes an exemplar successfully received is unclear;

5. How an exemplar guides the subsequent research is not explicitly analysed.

Correspondingly, a good reinterpretation of exemplar has to

$1^{\prime}$. explicate how an exemplar is constructed;

$2^{\prime}$. identify the constituents of an exemplar;

$3^{\prime}$. be instantiated by a detailed historical case-study;

$4^{\prime}$. explore the characteristics of a successfully accepted exemplar;

$5^{\prime}$. explain how the exemplar can guide subsequent research.

In other words, I not only have to tell what an exemplar is, what the components of an exemplar are, but also to explore how an exemplar is constructed, how an episode of the history of science can be characterised in terms of exemplars. Moreover, I shall discuss what the characteristics of a good exemplar are, which make it successfully accepted, and examine the instructive function of an exemplar.

I have argued that one advantage of a Kuhnian exemplar-based account of the history of science is that the significance of the problem-solution in the history and practice of science is well articulated and highlighted. Many of the scientific practices in history are oriented or inspired by some past successful problem-solutions. Kuhn's account of puzzle-solving does capture the "essence" of many, though not

17 There are a few attempts to employ the notion of exemplar to analyse some history cases. For example, Darden (1991) analyses the explanatory virtue of the hybrid crossing in terms of exemplar, while Skopek (2011) explores the pedagogical virtue of Mendel's work on peas in terms of exemplar. Unfortunately, the exemplars, for both Darden and Skopek, are simply construed as the examples in the textbook.

18 NIckles (2012, p. 128) asks a similar question: "What makes something an exemplar, a problem-cumsolution of the sort that is selected for inclusion in a textbook, widely cited by experts in the field, or the design of an instrument or a technique?".

19 As I have mentioned, Kuhn (1977) listed five main characteristics of a good theory (or a paradigm). However the theory (or the paradigm) here refers obviously to a disciplinary matrix rather than an exemplar. 
all, scientific practices in history. Therefore, I would reserve Kuhn's idea that a key constituent of an exemplar is a problem-solution. Furthermore, I argue that an exemplar as the fundamental unit shared by a scientific community should be more than a problem-solution. A well-defined problem itself is at least as important as its solution in the scientific practice. It also has as many normative functions as its solution does. In the history of science, new research problems usually play a vital role to guide the further practice, so the introduction of the new research problem itself is a great scientific achievement. For instance, in On the Origins of Species, Charles Darwin introduced many new research problems, which were never thought of or formulated before, like "How will the struggle for existence... act in regard to variation? Can the principle of selection, which we have seen is so potent in the hands of man, apply in nature?" (Darwin 1859, p. 80). In addition, puzzle-solving and problem-defining are two intertwined activities. As I shall show, an exemplary practice involves the mutually related activities of puzzle-solving and problem-defining. Moreover, it should be noted that problem-defining is much more than proposing a problem. In fact it usually consists of activities of problem-proposing (i.e. propose an initial problem), problemrefining (i.e. refine an initial problem), and problem-specification (i.e. make an initial problem into some more conceptually specific and experimentally testable problems). The well-defined research problems should be an essential constituent of an exemplar. Thus, my definition of exemplar is as follows:

An exemplar is a set of contextually well-defined research problems and the corresponding solutions.

Firstly, I take an exemplar as a set of contextually well-defined research problems and their solutions rather than a single problem and its solution. The reason is that a set of contextually well-defined problems and their solutions can better reflect the complex aspects of an exemplar as a scientific achievement. For example, we may argue that the Morgan school's research on Drosophila raises the problem of the patterns of inheritance of Drosophila and its solution. However, in a finer-grained analysis, the Morgan school's research on Drosophila raises a set of well-defined research problems (e.g. what is the expected distribution of phenotypes in a certain generation? What is the probability that a particular phenotype will result from a certain mating? What is the frequency of crossing over between two given loci in the chromosomes?) and their solutions.

Secondly, the reason why I define an exemplar as a set of "contextually" welldefined research problems and the corresponding successful solutions is that these research problems can only be well-defined and understood in the context of their solutions. In the process of constructing an exemplar, problem-defining and solutionsearching are not two independent activities. Rather these are two intertwined activities. Solution-searching is obviously dependent on the research problem, while the research problem can be redefined with the process of solution-searching such as conceptualisation and hypothesisation. 
Thirdly, an exemplar should not be understood in a purely theoretical sense. No exemplar can be constructed in an armchair. Any exemplar must have some nontheoretical components. ${ }^{20}$

Thus, a naïve version of the exemplar-based approach can be formulated accordingly as follows.

One should first analyse the history and practice of a science by identifying the research problems. Then, one needs to analyse the solutions and practical efforts to seek solutions, and then provide details about how they were applied to solve the problems.

It is obvious that such an exemplar-based approach is still too vague to be helpful or instructive in analysing the history and practice of science. Thus, I have to articulate the components of the solutions of an exemplar in greater detail. However, it should be noted that I do not think that the constituents of the solutions of an exemplar can be characterised in a monistic way. Scientists solve the problems in different ways, so it would be unwise for anyone to try to summarise some universally fundamental parts in their solutions. Therefore, what I would provide is rather a common recipe of an exemplar rather than a definition. By "a common recipe" I mean that an exemplar usually, but not exclusively, consists in such and such components. Here is my common recipe.

An exemplar has five main components: a vocabulary, which is a set of the concepts employed in the problems and solutions; a set of well-defined research problems; $a$ set of practical guides, which specify all the procedures and methodology as means to solve the problems; a set of hypotheses or models, which are proposed to solve the problems; and a set of patterns of reasoning, which indicate how to use other components to solve the problems. ${ }^{21}$

Three points have to be added here. Firstly, these five components are intertwined. For instance, the hypotheses are often formulated on the basis of the results of the experiments by employing the concepts in the vocabulary; the experiments are usually designed and undertaken with the purpose of solving the research problems (e.g. by testing the hypotheses); the concepts in the vocabulary are understood with the help of undertaking the experiments and applying the hypotheses, and so on. Secondly, the vocabulary of an exemplar does not suggest that all the concepts in the vocabulary are first introduced by the exemplar, though it is not unusual that the vocabulary of an exemplar has some pre-defined concepts. Thirdly, the hypotheses in the exemplar should not be narrowly construed as statements or propositions. Rather I refer to "hypotheses" as all kinds of theoretical constructions made by scientists. In history, scientists use different terms to name this kind of work like "hypotheses", "assumptions", "principles", "laws", "theories", "models", "mechanisms", etc.

Thus, correspondingly, the construction of an exemplary practice is a series of intertwined practices of experimentation, problem-defining, conceptualisation, hypothesisation, and reasoning. Experimentation is the practice of designing and

\footnotetext{
20 The conception of exemplar is certainly applicable to many disciplines, including logic and mathematics. But the one discussed in the paper is only applicable to the empirical sciences.

21 An example of the patterns of reasoning is the hypothetico-deductive (H-D) model of confirmation, which applies an H-D model of logic to confirm a hypothesis by designing and undertaking the experiments.
} 
undertaking the experiments. Problem-defining is the practice of defining and redefining the research problems. Conceptualisation is the practice of introducing a new conceptual scheme. Hypothesisation is the practice of theoretical construction to make an explanatory and predictive machinery. ${ }^{22}$ Again, all these practices are intertwined and cannot be understood as the independent activities of an exemplary practice.

Therefore, a common recipe for the exemplar-based approach can be summarised as follows.

In order to analyse the history of the practice of a scientific school, ${ }^{23}$ we first should identify the initial problem as the starting point of the research, ${ }^{24}$ and then trace the way of solving the initial problem by identifying the actual problems to be investigated and the way they occur in the practice, and analysing the process of problem-defining, conceptualisation, experimentation, hypothesisation, and reasoning involved. Then, we should detail the development of the intertwined practices in history to explore the development of a school of scientific practice.

Before completing my articulation of exemplar and the exemplar-based approach, I find one more problem, namely the problem of the reception of an exemplary practice, to be articulated. Why are some exemplary practices successfully received, while others totally neglected or abandoned after the acceptance in a period? What makes some exemplary practices so successfully accepted? What are the characteristics shared by those successfully accepted exemplary practices?

It is obvious that philosophy alone cannot provide the complete and comprehensive answers to these questions. Why and when an exemplary practice is recognised and well received by a community of scientists is complex and messy, both sociohistoriographically and philosophically. My interest here is not to attempt to look for universal and comprehensive answers to these questions. Rather, I aim to identify some intellectual characteristics shared by all well received exemplary practices in the history of science, if there are. I propose that all successfully accepted exemplars share (at least) two "intellectual" characteristics: repeatability and usefulness. A successfully accepted exemplary practice must be repeatable in the sense that all the practice of problem-defining, experimentation, conceptualization, hypothesisation, and reasoning can be repeatedly manipulated. On the other hand, a successfully accepted exemplary practice must be useful in the sense that some concepts in the vocabulary, some hypotheses, some research problems, some practical guides, or some patterns

\footnotetext{
22 Note that I have to emphasise here that there is no universal account of theoretical construction. We have to delve into the historical context to study the process of hypothesisation. For example. Some hypothesisaitons are better characterised as modelling, while others are better as the discovery of mechanism.

23 I take a scientific school as a research community, which is similar to Kuhn's paradigm (1970), Lakatos' research programme (1978), Laudan's research tradition (1977), and Massimi's scientific perspective (2016). Ptolemaic astronomy, Newtonian mechanics, and Mendelian genetics are good examples of scientific schools.

24 Although I emphasised that one of the most important contributions of an exemplary practice is the definition of research problems, it is unlikely for a scientist to begin his studies without an initial problem, which was a well-defined research problem. These initial problems might not be interesting at all for the subsequent development of the studies. A classical example is that the initial problem that inspired Morgan to conduct experiments on Drosophila was in search for an experimental approach to evolution, but he finally made a great achievement on solving the problems of Drosophila's heredity. It is also likely that an initial problem is re-formulated in new terms.
} 
of reasoning of the exemplary practice can be used as tools to solve other existing problems or establish new exemplary practices. As Nickles (2012, p. 128) indicates, "An exemplar candidate, like any tool, will gain status if it shows itself useful in a variety of related situations." It should be noted that repeatability and usefulness are minimally necessary, rather than sufficient conditions of a successfully received exemplary practice.

In summary, I define an exemplar as a set of contextually well-defined research problems and the corresponding solutions, which consists of a vocabulary, a set of well-defined research problems, a set of practical guides, a set of hypotheses or models, and a set of patterns of reasoning. I also propose that the development of a school of scientific practice can be analysed by identifying the initial research problem as the starting point of the research, and by articulating the way of solving the initial problem with the identification of the actual problems to be investigated and the way they occur in the practice, and by analysing the process of problem-defining, conceptualisation, experimentation, hypothesisation, and reasoning involved. In addition, repeatability and usefulness are two characteristics of a good exemplary practice. In the next section, I shall illustrate how this exemplar-based approach could be applied to analyse the development and progress in the origin of genetics.

\section{Case study: an exemplar-based account of the origin of genetics}

Understanding the significance of Gregor Johann Mendel has been a persistent problem in the history and philosophy of biology: In what sense is Mendel the founder of genetics? What did Mendel in fact contribute to the study of inheritance? What contribution did Mendel make to the history of genetics? Thanks to many historians' work (e.g. Brannigan 1979; Olby 1979; Callender 1988), the historiography of Mendel today has been radically revised. It is now a consensus that Mendel's concern was the development of pea hybrids rather than the problem of heredity in general (Olby 1979; Monaghan and Corcos 1990; Müller-Wille and Orel 2007). It is also accepted that the great rediscovery of Mendel's work in 1900 is in fact the introduction of Mendel's work into the study of heredity (Darden 1977; Olby 1985; Harwood 2000). Hugo de Vries, Carl Correns, and Erich von Tschermak, the "rediscoverers" of Mendel's work in 1900, all differ in their research problems (Corcos and Monaghan 1985, 1987; Monaghan and Corcos 1986). Therefore, the significance of Mendel in the history of genetics is even more confusing: How does Mendel's study on the development of pea hybrids contribute to the study of inheritance? What is the best way to provide a philosophical analysis of the "rediscovery" of Mendel's work? In particular, there is no plausible philosophical account of the origin of genetics, which is also compatible with our current best historiography. In this section, I shall introduce an exemplarbased account of the early development of genetics to show how the exemplar-based approach as a case of reviving Kuhn's legacy is helpful to contemporary philosophy of science.

In his original paper, Mendel (1865, p. 3) is very explicit on his purpose of the study of Pisum: to study the development of hybrids in their progeny. More specifically, the initial research problem for Mendel is: 
MP1. How could one "determine the number of different forms in which hybrid progeny appear, permit classification of these forms in each generation with certainty, and ascertain their numerical interrelationship"? (Mendel 1865, p. 4).

In order to make MP1 more experimentally testable and conceptually more specific problems for the further investigation, Mendel reformulates MP1 to a more specific sub-problem:

MP2. What are the changes for each pair of differing traits, selected in the preexperiment practice, in the offspring of Pisum? Or, what is the law deducible from the changes for each pair of differing traits selected in the successive generations? (Mendel 1865, p. 7).

With contextually intertwined activities by problem-defining, conceptualisation, experimentation, hypothesisation, and reasoning, Mendel established an exemplary practice on the study of pea hybridisation, summarised in Table 1.

The significance of Mendel's exemplary practice is to some extent overlooked until it was adopted by de Vries in his study of pangenesis. De Vries's initial problem (DP1) is to experimentally test the principle (DH1) that the specific characters of organisms are composed of distinct units (de Vries 1900a, b). It should be noted that DH1 is a reformulated version of the hypothesis $\left(\mathrm{DH}^{\prime}\right)$ in the theory of pangenesis (1889) that every hereditary characteristic has its special kind of pangen. De Vries had struggled to find a way of analysing the data based on his hybridisation experiments until he recognised that Mendel's problem specification (MP1 $\rightarrow$ MP2), concepts of dominance and recessiveness, and law of composition of hybrid fertilising cells (MH3) are useful. By incorporating Mendel's problem-defining, conceptualisation, and hypothesisation, de Vries constructed an exemplary practice on the study of pangenesis, which can be summarised as in Table 2 .

Correns' initial concern is the xenia question (CP1), that is, whether foreign pollen has a direct influence on the characteristics of the fruit and seed. In 1896 he began studying this problem in the case of Pisum. After reading Mendel's paper, Correns immediately recognised the relevance and usefulness of Mendel's work. The purpose of his 1900 paper is to test Mendel's work on Pisum. Thus, CP1 is specialised into another problem.

CP2. Is Mendel's observation and the law on Pisum verifiable?

In order to test Mendel's observation and analysis, Correns follows Mendel to focus on a pair of differing traits. (CG1) In other words, a more specific problem occurs.

CP3. Is Mendel's observation and law concerning a pair of differing traits confirmable?

Correns' exemplary practice on testing Mendel's study of Pisum can be summarised in Table 3.

By analysing Mendel's, de Vries', and Correns' exemplary practices, I argue that there are four constituents of Mendel's exemplary practice preserved (or preserved with minor modifications) and passed on in the successors' exemplary practices, despite their different initial research problems. And all these constituents well account for Mendel's major contributions to the history of genetics, summarised by the historians. 


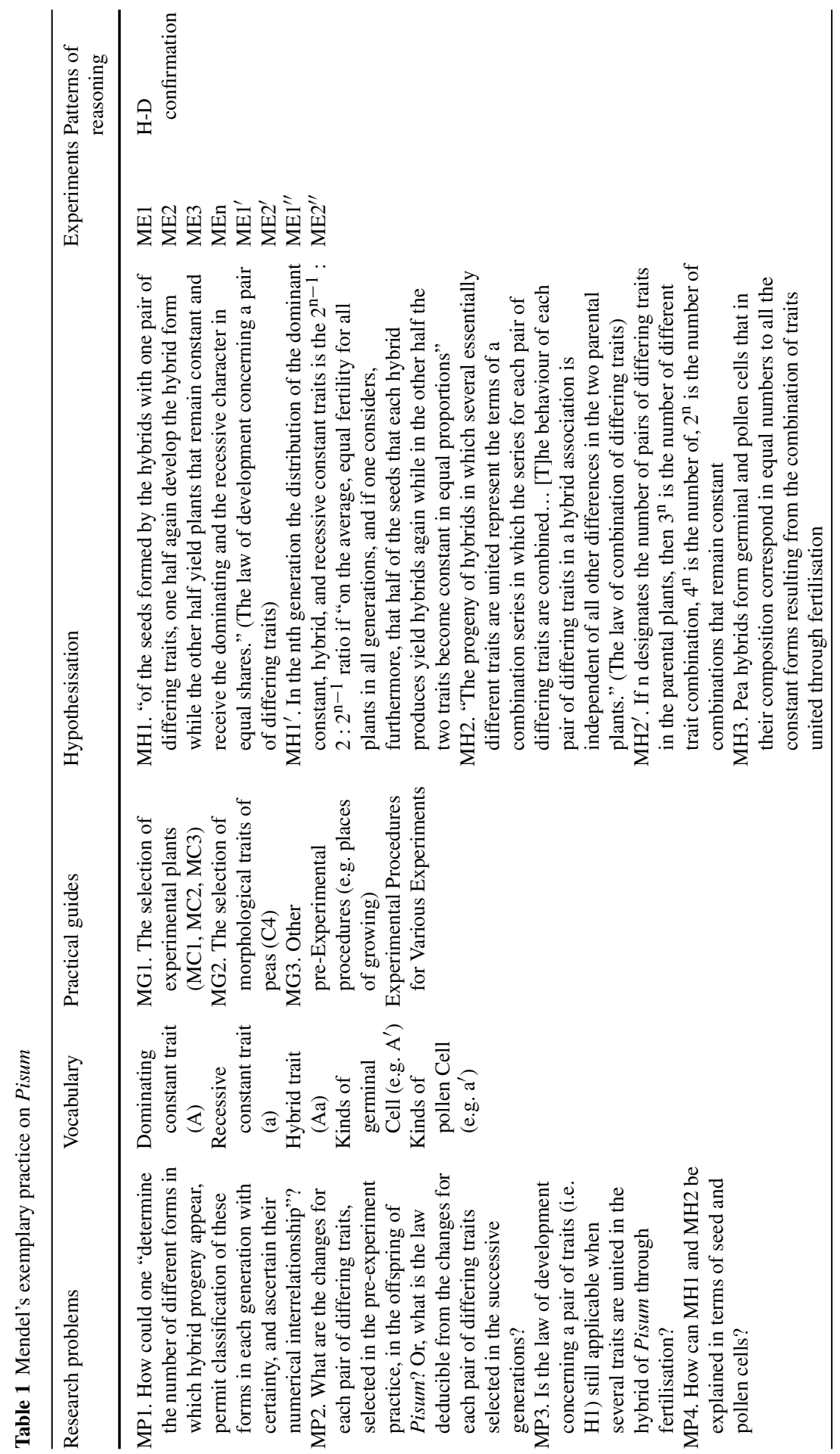




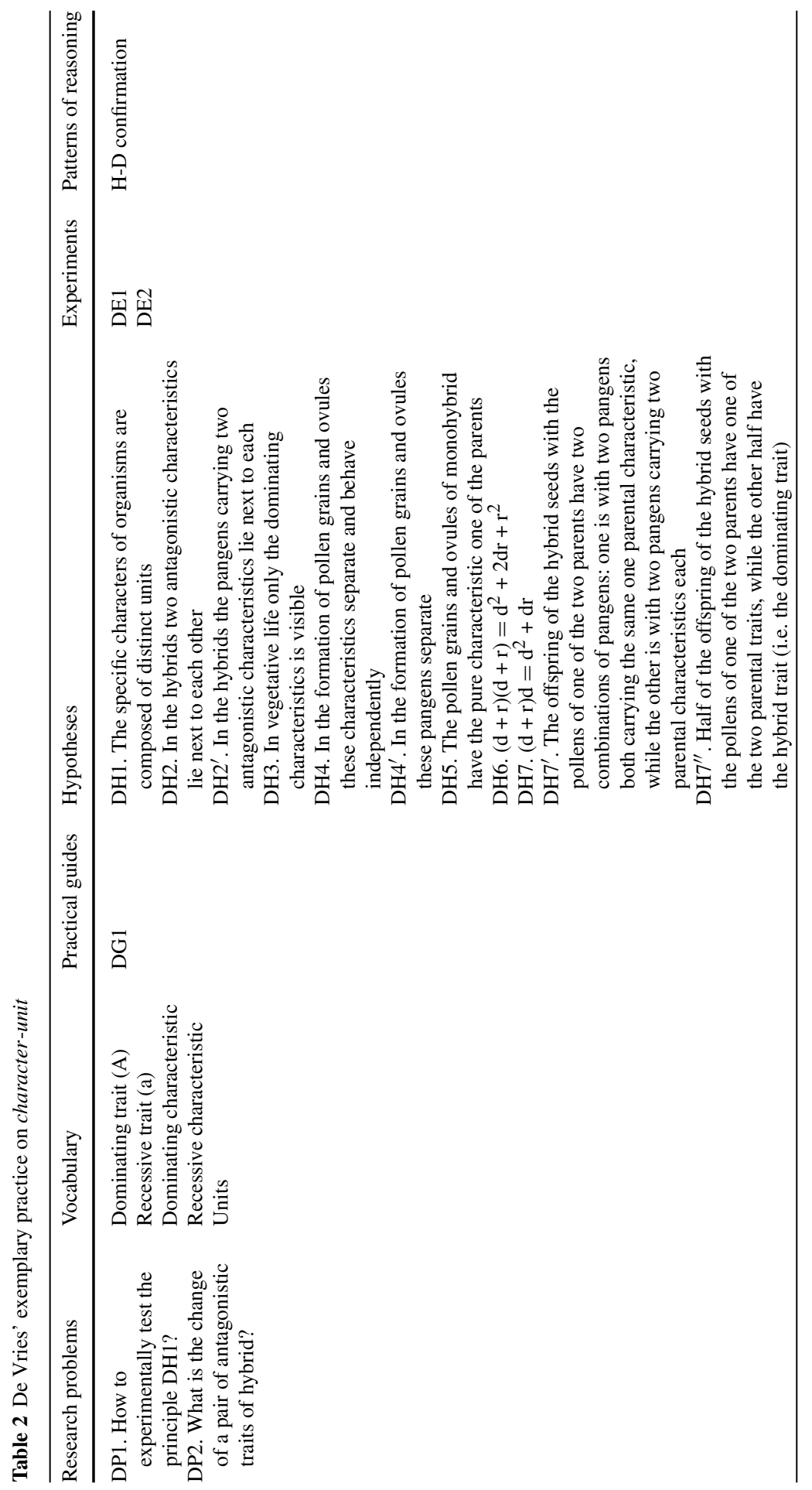


Table 3 Correns' exemplary practice on Mendel's Study of Pisum

\begin{tabular}{|c|c|c|c|c|c|}
\hline $\begin{array}{l}\text { Research } \\
\text { problems }\end{array}$ & Vocabulary & $\begin{array}{l}\text { Practical } \\
\text { guides }\end{array}$ & Hypotheses & Experiments & $\begin{array}{l}\text { Patterns of } \\
\text { reasoning }\end{array}$ \\
\hline \multirow{5}{*}{$\begin{array}{l}\text { CP1. Does foreign } \\
\text { pollen have a } \\
\text { direct influence } \\
\text { on the } \\
\text { characteristics } \\
\text { of the fruit and } \\
\text { seed? }\end{array}$} & Anlage & \multirow[t]{28}{*}{ CG1 } & $\mathrm{CH} 1$. In the fusion of the & \multirow{28}{*}{$\begin{array}{l}\text { CE1 } \\
\text { CE2 }\end{array}$} & \multirow{28}{*}{$\begin{array}{l}\text { H-D } \\
\text { confirmation }\end{array}$} \\
\hline & $\begin{array}{l}\text { Dominating } \\
\text { trait }(\mathrm{A})\end{array}$ & & $\begin{array}{l}\text { reproductive nuclei, the } \\
\text { anlage for the recessive }\end{array}$ & & \\
\hline & Recessive trait & & trait is suppressed by the & & \\
\hline & & & one for the dominating & & \\
\hline & $\begin{array}{l}\text { Dominating } \\
\text { anlage }\end{array}$ & & $\begin{array}{l}\text { trait. Prior to the } \\
\text { definitive formation of }\end{array}$ & & \\
\hline CP2. Is Mendel's & Recessive & & the reproductive nuclei & & \\
\hline observation and & anlage & & a complete separation of & & \\
\hline the law on & & & the two anlagen occurs, & & \\
\hline Pisum & & & so that one half of the & & \\
\hline verifiable? & & & reproductive nuclei & & \\
\hline CP3. Is Mendel's & & & receive the anlage for & & \\
\hline observation and & & & the recessive trait, the & & \\
\hline law concerning & & & other half the anlage for & & \\
\hline a pair of & & & the dominating trait & & \\
\hline differing traits & & & $\mathrm{CH} 2$. In the hybrid, & & \\
\hline confirmable? & & & reproductive cells are & & \\
\hline CP4. Is Mendel's & & & produced in which the & & \\
\hline observation and & & & anlagen for the & & \\
\hline law concerning & & & individual parental & & \\
\hline two or more pair & & & characteristics are & & \\
\hline of differing traits & & & contained in all possible & & \\
\hline confirmable? & & & combinations, but both & & \\
\hline CP4'. Is Mendel's & & & anlagen for the same & & \\
\hline LCD & & & pair of traits are never & & \\
\hline confirmable? & & & combination. Each & & \\
\hline CP5. Is Mendel's & & & combination occurs & & \\
\hline LCC universally & & & with approximately the & & \\
\hline applicable? & & & same frequency & & \\
\hline
\end{tabular}

First of all, as some historians (e.g. Olby 1979; Müller-Wille and Orel 2007) have already pointed out, one of Mendel's important achievements is that his approach to the study of the problem of development by focusing on the paired traits in the successive generations. Mendel's important observations and hypotheses are all about paired traits of hybrids and their progeny. This can be clearly illustrated as the problem-specification (MP1 $\rightarrow$ MP2). As Müller-Wille and Orel (2007, p. 211) indicate, "Mendel's focus on character pairs was not only an important methodological step, but had immediate consequences for his theorizing." The significance of Mendel's problem-specification (MP1 $\rightarrow$ MP2) is also reflected in its reception at the beginning of the twentieth century. Although de Vries, Correns, Tschermak, and Bateson were not studying hybrid development, all of them adopted Mendel's approach to concentrate on paired traits. It is no surprise that de Vries' problem-specification (DP1 $\rightarrow$ DP2) was indebted to Mendel's problem-specification (MP1 $\rightarrow$ MP2).

In every crossing experiment only a single character or a definite number of them is to be taken into consideration... for experimental purposes the simplest 
conditions are presented by hybrids whose parents differ from each other in one trait only (de Vries 1966, p. 108).

Tschermak (1900a) also adopted the Mendelian problem-specification to study his research problem. In particular, Bateson is explicit on the point that a significant lesson learnt from Mendel in the study of heredity is that of focusing on differing traits.

[T] he subjects of experiment should be chosen in such a way as to bring the laws of heredity to a real test. For this purpose the first essential is that the differentiating characters should be few, and that all avoidable complications should be got rid of. Each experiment should be reduced to its simplest possible limits... [I]t is certain that by similar treatment our knowledge of heredity may be rapidly extended (Bateson 1902, p. 16).

Thus, I argue that what de Vries, Correns, Teschermak, and Bateson in fact learnt from Mendel here is a way of refining a general problem into a more specific one. Despite beginning with different initial research problems, de Vries, Correns, and Bateson, influenced by Mendel's work (1865), all find that refining their initial problems into a better defined and more narrowly scoped problem on paired traits is helpful in the further investigation.

Another contribution of Mendel's work is his exemplary use of the terms "dominant" and "recessive" to conceptualise the paired traits and analyse the statistical relation of them. Though the phenomenon of dominance had been observed by many (e.g. Knight 1799; Goss 1824; Seton 1824) by the first half of the nineteenth century, Mendel was the first to conceptualise the phenomenon in terms of dominance/recessiveness, and record and analyse the statistical relation of dominant and recessive traits. Mendel's terminology was important for his work in the sense that it lay down the conceptual foundation for his analysis of data, recognition of the statistical regularity (e.g. the 3:1 ratio) and proposal of the hypotheses. It should be highlighted that the significance of Mendel's terminology and his statistical analysis are intertwined. The statistical analysis cannot be made without the terms "dominant" and "recessive", while the introduction of the concepts of dominance and recessiveness is not interesting if no statistical regularity is obtained.

Mendel's terminology also enlightened the study of heredity around 1900. The terms "dominant" and "recessive" were adopted by de Vries, Correns, Tschermak, and Bateson, though their usages are different from Mendel's in some respects (for a summary, see Table 4). Correspondingly, the statistical analysis of the dominating and recessive traits was also introduced into the study of heredity, especially by de Vries (1900a, b, c) and Bateson (1902).

I have to emphasise that the concepts of dominance and recessiveness are important in the origin of genetics because they are useful in conceptualisation, hypothesisation, and idealisation rather than because they are essential conceptual components, which are invariantly shared by both Mendel and the rediscoverers.

Thirdly, Mendel's law of composition of hybrid fertilising cells (MH3) was also particularly exemplary. What is really novel in Mendel's MH3 is the correspondence of 
Table 4 Different usages of the term "dominating/recessiveness"

\begin{tabular}{ll}
\hline & Dominating/recessiveness \\
\hline $\begin{array}{l}\text { Morphological traits } \\
\text { Morphological traits with a certain behaviour in } \\
\text { the progeny }\end{array}$ & $\begin{array}{l}\text { Mendel, de Vries, Correns, Tschermak, Bateson } \\
\text { Mendel }\end{array}$ \\
$\begin{array}{l}\text { Hereditary characteristics } \\
\text { Hereditary material }\end{array}$ & $\begin{array}{l}\text { De Vries } \\
\text { Correns, Bateson }\end{array}$ \\
\hline
\end{tabular}

the statistical relations of morphological traits and of germinal and pollen cells. ${ }^{25}$ The morphological-cellular correspondence proposed by Mendel became a key to advance the study of heredity three decades later. The biggest difficulty identified by Bateson (1902) in the study of heredity at the turn of the twentieth century was the lack of a reliable approach to study the physical basis of heredity. In fact there were a few theories of heredity concerning the physical basis. Weismann's theory of germ-plasm (1892) and de Vries' theory of pangenesis (1889) are two representative ones. However, neither provided a feasible way to test the hypothesis. In particular, the relation of visible characters and invisible "physical basis of heredity" is untestable experimentally. The state of art of the study of heredity around 1900 is, as Bateson (1902, p. 3) neatly summarises, "[n]o one has yet any suggestion, working hypothesis, or mental picture that has thus far helped in the slightest degree to penetrate beyond what we see." In 1900, de Vries adopted and revised Mendel's hypothesis on the morphological-cellular correspondence to support his theory of pangenesis. In addition, de Vries also limited the application of his trait-characteristics correspondence in the case of true hybrids. Correns made "a significant step beyond Mendel" by reformulating Mendel's hypothesis as a trait-anlage correspondence $(\mathrm{CH} 1, \mathrm{CH} 2)$, though he was not clear on the implication of this reformulation in the study of heredity. Bateson was the first to make a sophisticated attempt to incorporate Mendel's morphological-cellular correspondence with the study of heredity. Firstly, Bateson revised Mendel's hypothesis as a trait-paired allele determination. It is determination rather than correspondence, because Bateson explicitly talked of "the bearers of the character". Secondly, in contrast to the limited applicability of Mendel's correspondence, Bateson's trait-paired alleles determination is applicable broadly in certain phenomena of alternative inheritance. Though Mendel's morphological-cellular correspondence was not adopted without modification in de Vries', Correns', and Bateson's work, it was really helpful to set out an approach to work on the "inward and essential nature" of heredity.

Fourthly, Mendel's other contribution to the study of heredity in 1900 is his exemplary mathematical approach. Mendel denotes the dominant (constant) trait A, the hybrid trait $\mathrm{Aa}$, the recessive (constant) trait a, and the distribution of these traits in the $\mathrm{F}_{2}$ generation $(\mathrm{A}+2 \mathrm{Aa}+\mathrm{a})$. All these symbolic notations are much more important and useful than at first appears. All Mendel's three laws can be formulated in the equations in terms of these notations.

\footnotetext{
25 It is worth noting that correspondence is a weaker notion than determination. Mendel never used the notion of determination, or causation in $\mathrm{MH} 3$.
} 
MH1: $A+2 A a+a$

MH2: $\begin{aligned} &(A+2 A a+a)(B+2 B b+b)= A B+A b+a B+2 A B b+2 a B b \\ &+2 A a B+2 A a B+4 A a B b \\ & \text { MH3: } \frac{A^{\prime}}{A^{\prime}}+\frac{A^{\prime}}{a^{\prime}}+\frac{A^{\prime}}{a^{\prime}}+\frac{a^{\prime}}{a^{\prime}}=A+2 A a+a\end{aligned}$

Moreover, Mendel's MH1 and MH2 are introduced and articulated with the help of these notations and the mathematical manipulation of these. Mendel's mathematical notation was also adopted and further developed by de Vries. The distribution of characteristics in the $F_{2}$ generation is formulated by de Vries as $d^{2}+2 d r+r^{2}$. The move from $\mathrm{A}+2 \mathrm{Aa}+\mathrm{a}$ to $\mathrm{d}^{2}+2 \mathrm{dr}+\mathrm{r}^{2}$ was a breakthrough in the history of genetics. The equation $(d+r)(d+r)=d^{2}+2 d r+r^{2}$ implicitly suggests the phenomenon of the separation of hereditary characteristics within pollen grains and ovules. This lays down the cornerstone for a later conception of particulate inheritance. Mendel's laws, and the concepts of allelomorph (Bateson 1902, 1909), factor (Punnett 1905; Morgan et al. 1915), and gene (Morgan 1926) were all articulated with the help of similar notations. Although, as many have pointed out, Mendel himself never had the conception of pairs of hereditary elements determining the morphological trait, his mathematical approach still played an indispensable role in the founding of genetics as a school of scientific practice. Therefore, as I have shown, Mendel's four significant contributions, namely, the focus on a pair of differing traits, the conceptions of dominance and recessiveness and their statistical relation, the morphological-cellular correspondence, and the mathematical approach, can be well accounted as problem-specification, conceptualisation, and hypothesisation.

To sum up, I argue that Mendel's contribution to the history of genetics is an exemplary practice of the development of pea hybrids in their progeny. More specifically, Mendel introduced a set of contextually well-defined research problems on the development of hybrids in their progeny and the corresponding solutions, and some components of his exemplary practice greatly inspired and influenced de Vries', Correns', Tschermak', and Bateson's work, and lay down the cornerstone for the study of heredity in the twentieth century. In particular, as I have argued earlier in this section, Mendel's focus on a pair of differing traits, the proposal of the conceptions of dominance and recessiveness and their statistical relation, the introduction of the morphological-cellular correspondence, and his mathematical approach made an enormous impact on de Vries', Correns' and Bateson's' work on heredity. Similarly, de Vries', Correns', and Bateson's contribution can also be characterised as the exemplary practices, which also inspired and influenced the successors' work (e.g. Castle and Allen 1903; Castle 1903; Punnett 1905; Raynor and Doncaster 1905; Hurst 1906) on heredity in the first decade of the twentieth century. Therefore, the origin of genetics from Mendel to Bateson, I argue, can be characterised as a chain of exemplary practices. 
In the origin of genetics, the earlier exemplary practices are accepted and learnt by the successor practitioners. It should be noted that to say that the practitioners accept an exemplary practice does not mean that all the components of that exemplary practice are accepted and shared dogmatically. Instead what is accepted and shared by all practitioners is the way of defining the problems and of solving these problems. In the case of the origin of genetics, what de Vries, Correns, Tschermak, and Bateson all shared and accepted is Mendel's problem-defining and problem-solving. Nevertheless, they still differed in how to understand the components of Mendel's exemplary practice and how to use them (or some of them) to solve their problems. For the "rediscoverers", Mendel's conceptualisation, hypothesisation, experimentation, and reasoning are just tools to solve Mendel's problems, but some of the tools were useful to their own research problems. Thus, Mendel's vocabulary, hypotheses, practical guides, experiments and patterns of reasoning are accepted as tools to solve Mendel's problem of hybrid development in their progeny and to solve successors' problems. As I have shown, the rediscoverers' acceptance of Mendel's exemplary practice is mainly due to its repeatability and usefulness. In addition, to say that the exemplary practices are accepted does not mean that they are accepted invariantly by all the late practitioners. For example, it would be plausible to argue that de Vries and Bateson accepted and worked on the basis of Mendel's exemplar practice, while Hurst and Punnett accepted and worked on the basis of Bateson's exemplary practice rather than Mendel's. This is why I argue that the origin of genetics is better characterised as a chain of exemplary practices rather than a set of exemplary practices.

To some extent, characterising Mendel's contribution as the introduction of new problems and their solutions is not a completely new idea. In particular, the significance of Mendel's introduction of new research problems had been highlighted by many historians (e.g. Sandler and Sandler 1985; Bowler 1989). In particular, Sandler and Sandler (1985, p. 69) explicitly pointed out that "Mendel ... defined his problem in purely genetic terms, and produced a correct and amazingly complete answer." However, one crucial difference between Sandlers' and my interpretation is that Sandlers' focus is mainly historical. Little is said about what the problem is and what the answer is, or how the problem and its solution influence the successor's work methodologically, conceptually, theoretically, etc. And this is what the reinterpretation of Kuhn's exemplar can contribute to examine these issues.

To sum up, so far I have argued that Mendel's contribution can be characterised as an introduction to new research problems and their corresponding solutions. The origin of genetics from Mendel to Bateson ${ }^{26}$ is accordingly understood as a chain of exemplary practices. This is a good example of how a reinterpretation of Kuhn's exemplar can be helpful in our understanding of scientific change and progress in the history of science.

\footnotetext{
26 I have to emphasise that the origin of genetics from Mendel to Bateson discussed in this paper is definitely not a complete and comprehensive picture of the origin of genetics. As the title of Olby's book Origins of Mendelism has suggested, there are multiple origins of genetics. What I focus on here is only one path to genetics. More precisely speaking, my task is to explore a new exemplar-based way to analyse and understand the development from Mendel's (1865), de Vries' (1900a, b, c), Correns' (1900), Tschermak's (1900a, b) to Bateson's work (1902).
} 


\section{Conclusion}

In summary, firstly I argue that Kuhn made two major novel contributions to the philosophy of science in 1960s: the introduction of the conception of paradigm as an alternative to theory to analyse and understand the practice and history of science; and the proposal of the paradigm-based incommensurability thesis. Secondly, I argue that Kuhn's conceptual/terminological turn (from paradigm to theory) underlies the shift of Kuhn's focus upon the incommensurability from the semantic, methodological and cognitive aspects to the semantic aspect only, and underlies the methodological turn from a naturalistic approach and a priori approach. I thus argue that it is Kuhn's failure to explore and articulate his novel concept of paradigm as exemplar which makes the incommensurability thesis less fruitful and plausible. Since the introduction of the conception of exemplar is, as Kuhn himself recognizes, his most novel and important contribution, I argue that it is also an important legacy for contemporary philosophy of science. Finally, I have proposed a new interpretation of exemplar, and shown how an exemplar-based approach can help to understand the development and progress in the history of science. Along with Bird, I argue that there is still much more to do on Kuhn's legacy. Kuhn's philosophy is not dead, and should not be dead.

Acknowledgements I would like to thank Jonathon Hricko and two anonymous referees for the helpful comments. I also thank Michael Buttolph and Hugh MacKenzie for proofreading the final manuscript.

Open Access This article is distributed under the terms of the Creative Commons Attribution 4.0 International License (http://creativecommons.org/licenses/by/4.0/), which permits unrestricted use, distribution, and reproduction in any medium, provided you give appropriate credit to the original author(s) and the source, provide a link to the Creative Commons license, and indicate if changes were made.

\section{References}

Babich, B. E. (2003). From Fleck's Denkstil to Kuhn's Paradigm: Conceptual Schemes and Incommensurability. International Studies in the Philosophy of Science, 17(1), 75-92.

Bateson, W. (1902). Mendel's principles of heredity: A defence. Cambridge: Cambridge University Press. Bateson, W. (1909). Mendel's principles of heredity. Cambridge: Cambridge University Press.

Bird, A. (2002). Kuhn's wrong turning. Studies in History and Philosophy of Science, 33(3), 443-463.

Bird, A. (2005). Naturalizing Kuhn. Proceedings of the Aristotelian Society, 105(1), 99-117.

Bird, A. (2008). Incommensurability Naturalized. In Léna Soler, Howard Sankey, \& Paul Hoyningen-Huene (Eds.), Rethinking scientific change and theory comparison: Stabilities, ruptures, incommensurabilities? (Boston studies in the philosophy and history of science) (pp. 21-39). Dordrecht: Springer.

Bowler, P. J. (1989). The Mendelian revolution: The emergence of hereditarian concepts in modern science and society. London: The Athlone Press.

Brannigan, A. (1979). The reification of Mendel. Social Studies of Science, 9(4), 423-454.

Callender, L. A. (1988). Gregor Mendel: An opponent of descent with modification. History of Science, 26(1), 41-75.

Castle, W. E. (1903). Mendel's law of heredity. Science, 18(456), 396-406.

Castle, W. E., \& Allen, G. M. (1903). The heredity of albinism. Proceedings of the American Academy of Arts and Sciences, 38(21), 603-622.

Chang, H. (2012). Incommensurability: Revisiting the chemical revolution. In Vasso Kindi \& Theodore Arabatzis (Eds.), Kuhn's the structure of scientific revolutions revisited (pp. 153-176). New York and London: Routledge.

Chang, H. (2014). Epistemic activities and systems of practice: Units of analysis in philosophy of science after the practical turn. In Léna Soler, Sjoerd Zwart, Michael Lynch, \& Vincent Israel-Jost (Eds.), 
Science after the practice turn in the philosophy, history and social studies of science (pp. 67-79). New York and London: Rodopi.

Corcos, A. F., \& Monaghan, F. V. (1985). Role of de Vries in the recovery of Mendel's work I. Was de Vries really an independent discoverer of Mendel? Journal of Heredity, 76(3), 187-190.

Corcos, A. F., \& Monaghan, F. V. (1987). Correns, an independent discovery of Mendelism? II. Was Correns a real interpreter of Mendel's paper? Journal of Heredity, 78(6), 404-405.

Correns, C. (1900). G. Mendels Regel über das Verhalten der Nachkommenschaft der Rassenbastarde. Berichte der Deutschen Botanischen Gesellschaft, 18(4), 158-168.

Darden, L. (1977). William Bateson and the promise of Mendelism. Journal of the History of Biology, 10(1), 87-106.

Darden, L. (1991). Theory change in science: Strategies from Mendelian genetics. Oxford: Oxford University Press.

Darden, L., \& Maull, N. (1977). Interfield theories. Philosophy of Science, 44(1), 43-64.

Darwin, C. (1859). On the origin of species. London: John Murray.

de Vries, H. (1889). Intracellulare pangenesis. Jean: Gustav Fischer.

de Vries, H. (1900a). Das Spaltungsgesetz der Bastarde (Vorlaufige Mittheilung). Berichte der Deutschen Botanischen Gesellschaft, 18(3), 83-90.

de Vries, H. (1900b). Sur La Loi de Disjonction Des Hybrides. Comptes Rendus de I'Academie Des Sciences (Paris), 130, 845-847.

de Vries, H. (1900c). Sur Les Unités Des Caractères Spécifiques et Leur Application À L'étude Des Hybrides. Revue Générate de Botanique, 12, 257-271.

de Vries, H. (1966). The law of segregation of hybrids. In C. Stern \& E. R. Sherwood (Eds.), The origin of genetics: A mendel source book (E. Stern, Trans., pp. 107-17). San Francisco, CA: W. H. Freeman and Company.

Feyerabend, P. (1962). Explanation, reduction, and empiricism. In Herbert Feigl \& Grover Maxwell (Eds.), Scientific explanation, space, and time (Minnesota studies in the philosophy of science, Volume III) (pp. 28-97). Minneapolis, MN: University of Minnesota Press.

Fleck, L. (1927). O Niektórych Swoistych Cechach Myślenia Lekarskiego. Archiwum Hisrorii I Filozofii Medycyny Oraz Historii Nauk Przyrodniczych, 6, 55-64.

Fleck, L. (1935). Entstehung und Entwicklung einer wissenschaftlichen Tatsache: Einführung in die Lehre Vom Denkstil und Denkkollektiv. Basel: Benno Schwabe \& Co.

Fleck, L. (1939). Odpowiedź Na Uwagi Tadeusza Bilikiewicza. Przeglad Wspolczesny, 8-9, 149-156.

Giere, R. (2011). History and philosophy of science: Thirty-five years later. In Seymour Mauskopf \& Tad Schmaltz (Eds.), Integrating history and philosophy of science: Problems and prospects (pp. 59-65). Dordrecht: Springer.

Goss, J. (1824). On the variation in the colour of peas, occasioned by cross impregnation. Transactions of the Horticultural Society of Londonociety of London, 5, 234-236.

Harwood, J. (2000). The rediscovery of mendelism in agricultural context: Erich von Tschermak as PlantBreeder. Comptes Rendus de l'Academie Des Sciences-Serie III, 323(12), 1061-1067.

Hurst, C. C. (1906). On the inheritance of coat colour in horses. Proceedings of the Royal Society of London. Series B, 77(519), 388-394.

Knight, T. A. (1799). An account of some experiments on the fecundation of vegetables. Philosocial Transactions of the Royal Society of London, 89, 195-204.

Knoblauch, H. (2010). Wissenssoziologie. Stuttgart: UTB.

Kuhn, T. S. (1962). The structure of scientific revolutions (1st ed.). Chicago, IL: University of Chicago Press.

Kuhn, T. S. (1970). The structure of scientific revolutions (2nd ed.). Chicago, IL: University of Chicago Press.

Kuhn, T. S. (1974). Second thoughts on paradigms. In F. Suppe (Ed.), The structure of scientific theories (1st ed., pp. 459-482). Urbana, IL: University of Illinois Press.

Kuhn, T. S. (1977). Objectivity, value judgment, and theory choice. In The Essential Tension: Selected studies in scientific tradition and change (pp. 320-339). Chicago, IL: University of Chicago Press.

Kuhn, T. S. (1979). Foreword. In T. J. Trenn \& R. K. Merton (Eds.), Genesis and development of a scientific fact (pp. vii-xii). Chicago, IL: University of Chicago Press.

Kuhn, T. S. (1982). Commensurability, comparability, communicability. In PSA: Proceedings of the biennial meeting of the Philosophy of Science Association (pp. 669-688).

Kuhn, T. S. (1983). Rationality and theory choice. Journal of Philosophy, 80(10), 563-570. 
Kuhn, T. S. (1987). What are scientific revolutions? In L. Krüger, L. Daston, \& M. Heidelberger (Eds.), The probabilistic revolution (pp. 7-22). Cambridge: Cambridge University Press.

Kuhn, T. S. (1989). Possible worlds in history of science. In S. Allen (Ed.), Possible worlds in humanities, arts and sciences (pp. 9-32). Berlin: De Gruyter.

Kuhn, T. S. (1990). The road since structure. PSA Proceedings of the Biennial Meeting of the Philosophy of Science Association, 2, 3-13. https://doi.org/10.1093/bjps/55.1.175.

Kuhn, T. S. (1993). Afterwords. In Paul Horwich (Ed.), World change: Thomas Kuhn and the nature of science (pp. 311-341). Cambridge, MA: MIT Press.

Kuhn, T. S. (2000a). The natural and the human sciences. In James Conant \& John Haugeland (Eds.), The road since structure (pp. 216-223). Chicago, IL: University of Chicago Press.

Kuhn, T. S. (2000b). The trouble with the historical philosophy of science. In James Conant \& John Haugeland (Eds.), The road since structure (pp. 105-120). Chicago, IL: University of Chicago Press.

Lakatos, I. (1968). Criticism and the methodology of scientific research programmes. Proceedings of the Aristotelian Society, 69, 149-186.

Lakatos, I. (1978). Falsification and the methodology of scientific research programmes. In John Worrall \& Greogry Currie (Eds.), The methodology of scientific research programme (pp. 8-101). Cambridge: Cambridge University Press.

Laudan, L. (1977). Progress and its problems. Berkeley: University of California Press.

Massimi, M. (2016). Four kinds of perspectival truth. Philosophy and Phenomenological Research. https:/ /doi.org/10.1111/phpr.12300.

Mendel, G. (1865). Versuche Über Pflanzenhybriden. Verhandlungen Des Naturforschenden Vereins Brünn, 4(Abhandlungen), 3-47.

Monaghan, F. V., \& Corcos, A. F. (1986). Tschermak: A non-discoverer of Mendelism, I. An historical note. Journal of Heredity, 77, 468-469.

Monaghan, F. V., \& Corcos, A. F. (1990). The real objective of Mendel's paper. Biology and Philosophy, $5(3), 267-292$.

Morgan, T. H. (1926). The theory of the gene. New Haven, CT: Yale University Press.

Morgan, T. H., Sturtevant, A. H., Muller, H. J., \& Bridges, C. B. (1915). The mechanism of mendelian heredity. New York: Henry Holt and Company.

Mößner, N. (2011). Thought styles and paradigms: A comparative study of Ludwik Fleck and Thomas S. Kuhn. Studies in History and Philosophy of Science, 42(2), 362-371.

Müller-Wille, S., \& Orel, V. (2007). From Linnaean species to Mendelian factors: elements of hybridism, 1751-1870. Annals of Science, 64(2), 171-215.

Nagel, E. (1961). The structure of science: Problems in the logic of scientific explanation. New York: Harcourt, Brace \& World.

Nickles, T. (2003). Normal science: From logic to case-based and model-based reasoning. In Thomas Nickles (Ed.), Thomas Kuhn (pp. 142-177). Cambridge: Cambridge University Press.

Nickles, T. (2012). Some puzzles about Kuhn's exemplars. In Vasso Kindi \& Theodore Arabatzis (Eds.), Kuhn's the structure of scientific revolutions (pp. 112-133). London and New York: Routledge.

Olby, R. (1979). Mendel no Mendelian? History of Science, 17(1), 53-72.

Olby, R. (1985). Origins of Mendelism (2nd ed.). Chicago, IL: University of Chicago Press.

Polanyi, M. (1966). The tacit dimension. London: Routledge and Kegan Paul.

Popper, K. (1959). The logic of scientific discovery (1st ed.). London: Hutchinson \& Co.

Punnett, R. C. (1905). Mendelism. London: Macmillan and Co., Limited.

Raynor, G. H., \& Doncaster, L. (1905). Experiments on heredity and sex-determination in Abraxas Grossulariata. In Report of the 74th meeting of the British Association for the Advancement of Science, Cambridge 1904 (pp. 594-595). London: John Murray.

Rouse, J. (2003). Kuhn's philosophy of scientific practice. In Thomas Nickles (Ed.), Thomas Kuhn (pp. 101-121). Cambridge: Cambridge University Press.

Sandler, I., \& Sandler, L. (1985). A conceptual ambiguity that contributed to the neglect of Mendel's paper. History and Philosophy of the Life Sciences, 7(1), 3-70.

Sankey, H. (1993). Kuhn's changing concept of incommensurability. Bristish Journal for the Philosophy of Science, 44(4), 759-774.

Sankey, H. (1994). The incommensurability thesis. Aldershot: Avebury.

Seton, A. (1824). Note by the secretary. Transactions of the Horticultural Society of London, 5, 236-237.

Skopek, J. M. (2011). Principles, exemplars, and uses of history in early 20th century genetics. Studies in History and Philosophy of Biological and Biomedical Sciences, 42(2), 210-225. 
Soler, L., Zwart, S., Lynch, M., \& Israel-Jost, V. (2014). Introduction. In Léna Soler, Sjoerd Zwart, Michael Lynch, \& Vincent Israel-Jost (Eds.), Science after the practice turn in the philosophy, history and social studies of science (pp. 1-43). New York: Routledge.

Suppe, F. (Ed.). (1977). The structure of scientific theories (2nd ed.). Urbana, IL: University of Illinois Press.

Toulmin, S. E. (1972). Human understanding. Princeton, NJ: Princeton University Press.

Tschermak, E. (1900a). Über künstliche Kreuzung bei Pisum Sativum. Berichte der Deutschen Botanischen Gesellschaft, 18(6), 232-239.

Tschermak, E. (1900b). Über künstliche Kreuzung bei Pisum Sativum. Zeitschrift für das Landwirtschaftliche Versuchswesen in Oesterreich, 3, 465-555.

Waters, C. K. (2014). Shifting attention from theory to practice in philosophy of biology. In M. C. Galavotti, D. Dieks, W. J. Gonzalez, S. Hartmann, T. Uebel, \& M. Weber (Eds.), New directions in the philosophy of science (pp. 121-139). Dordrecht: Springer.

Weismann, A. (1892). Das Keimplasma: Eine Theorie der Vererbung. Jena: Gustav Fischer. 